\title{
Multisystem Inflammatory Syndrome in Children with COVID-19-Positive Antibodies
}

\author{
Bushra Yacop Mustafa Helmi Maysa Saleh \\ Pediatric Department, Latifa Women and Children Hospital, Dubai, United Arab Emirates
}

\section{Keywords}

Multi-inflammatory syndrome of children · Severe acute respiratory syndrome coronavirus $2 \cdot$ Coronavirus disease 19

\begin{abstract}
The epidemiology of multisystem inflammatory syndrome in children (MIS-C) and the provisional case definition are still being updated by the WHO. There is no solid evidence regarding the clinical presentations, severity, and outcomes. This case report tackles a 4-year-old female. Her main manifestations were persistent high-grade fever $\left(40.0^{\circ} \mathrm{C}\right)$, diarrhea, poor oral intake, fatigue, and less activity with mucocutaneous involvement. Blood test revealed elevated inflammatory markers, as well as D-dimer, cardiac enzymes, and IL-6 with lymphopenia. She had a history of coronavirus disease (COVID-19) infection 4 weeks prior to admission. We describe a patient diagnosed as MIS-C or so-called SARSCoV-2-induced Kawasaki-like hyperinflammatory syndrome. It seems to be caused by delayed response to SARS-CoV-2. It mimics Kawasaki disease, with unique presentations, such as diarrhea, capillary leak, and myocardial dysfunction, complicated by macrophage activation syndrome. Eventually, she
\end{abstract}

karger@karger.com www.karger.com/dmj

Karger $\stackrel{\text { ' }}{5}$

GOPEN ACCESS
(C) 2021 The Author(s)

Published by S. Karger AG, Basel

This is an Open Access article licensed under the Creative Commons Attribution-NonCommercial-4.0 International License (CC BY-NC) (http://www.karger.com/Services/OpenAccessLicense), applicable to the online version of the article only. Usage and distribution for commercial purposes requires written permission. completely improved with aggressive management including intravenous immunoglobulin, intravenous methylprednisolone, anti-IL-6, and aspirin. This is one of the early cases presented to our tertiary hospital fulfilling the CDC criteria of MIS-C. Based on this case, we suggest that pediatricians need to be aware of such clinical presentations and early referral to tertiary care health facility for further diagnosis and management. MIS-C is not common but a highly critical complication of COVID-19 infection in pediatrics resulting in life-threatening illnesses. Knowledge about the wide spectrum of presenting clinical manifestations, disease severity, and early detection and management is crucial to prevent a serious outcome.

(c) 2021 The Author(s).

Published by S. Karger AG, Basel

\section{Introduction}

The quickly developing pandemic related with severe acute respiratory syndrome coronavirus 2 (SARS-CoV-2) has prompted $>125$ million confirmed cases and $>2.5$ million deaths. To date, in the UAE, there have been 497,154 confirmed cases of COVID-19 with 1,554 deaths, as reported to the WHO $[1,2]$. There have been relatively few 
recorded cases of infants known to have COVID-19; mild disease has been reported by those who are infected [3]. Strong evidence associating underlying conditions with serious disease in children is still uncertain [4].

Clusters of children and adolescents needing intensive unit treatment with a multisystem inflammatory disorder similar to Kawasaki disease and toxic shock syndrome have been identified in reports from Europe and North America. Case reports and small studies have described a presentation of acute illness associated with a hyperinflammatory syndrome, leading to shock and multiorgan failure. Current hypotheses are that this syndrome may be related to COVID-19 based on positive serology laboratory testing in most of the patients [3].

This one of the first cases, which presented to our hospital fulfilling the CDC criteria of multisystem inflammatory syndrome in children (MIS-C). Detailed discussion about such cases will draw attention of the clinicians about the presentation, progress, and management plan.

\section{Case Presentation}

A 35-month-old female previously healthy presented to our tertiary hospital with a history of fever up to $40.0^{\circ} \mathrm{C}$ for 4 days with weakness, less active, abdominal pain, nonbloody diarrhea, poor appetite, vomiting, and erythematous papular skin rash on the lower abdomen. She had positive PCR test for SARS-CoV-2 4 weeks prior to admission with mild fever for 2 days and no other complaints. She was home quarantined for 14 days. Her 2 elder sisters showed positive PCR for SARS-CoV-2 and were asymptomatic. She had no significant past medical or surgical history and vaccination up to date with normal growth and development.

The child was admitted to the pediatric intensive care unit (PICU). She appeared tired, lethargic, sleepy, moderately dehydrated with mild pallor, cracked lips, normal conjunctiva, mild swelling of the dorsum of the hands and feet, and erythematous papular rash over the skin of the lower abdomen. She had tachypnea and tachycardia. Capillary refill was $3 \mathrm{~s}$; the vital signs were blood pressure $95 / 46 \mathrm{~mm} \mathrm{Hg}$ (normal), pulse $136 \mathrm{~b} / \mathrm{min}$, tympanic temperature $37.8^{\circ} \mathrm{C}\left(100^{\circ} \mathrm{F}\right)$, respiratory rate $32 / \mathrm{min}$, and $\mathrm{SPO}_{2}$ $95 \%$; height was $97 \mathrm{~cm}$ and weight $14.8 \mathrm{~kg}$. Cardiovascular examination revealed normal heart sound, tachycardia, no murmur, and no gallop rhythm; respiratory system examination revealed mild tachypnea with bilateral equal air entry; the abdomen was soft and no palpable organ; joints were normal; she was sleepy but arousal, irritable, and crying while awake. All investigations were collected including nasopharyngeal swab PCR for SARS-CoV-2 and septic workup.

She was kept nil by mouth with close monitoring of intake and output. She was started on IV antibiotics, IV fluid with electrolyte correction, and other supportive measures with close monitoring. The impression of Kawasaki disease versus MIS-C was highly suspicious. She was started on intravenous immunoglobulin $2 \mathrm{~g} / \mathrm{kg} \mathrm{IV}$ infusion.

Multisystem Inflammatory Syndrome in Children
The blood film reported the following: WBCs showed leucopenia/severe absolute lymphopenia; many reactive lymphocytes and neutrophils showed a shift to left, toxic granulations, and many showed vacuolation; RBCs were microcytic hypochromic, platelets were slightly reduced on smear. Imp: pancytopenia and reactive picture. PCR for SARS-CoV-2 came negative. Urine routine showed the following: protein $1+$, glucose negative, ketone $2+$ $\mathrm{RBC} / \mathrm{HPF} 3-5$, stool routine, blood and mucous negative, $\mathrm{RBC} /$ HPF 5-10, and blood group A negative.

ECG and ECHO reported mitral regurgitation; ejection fraction (EF) 65\%, and normal coronary arteries. SARS-CoV-2 antibodies were collected. Chest X-ray reported prominent bronchovascular markings and normal heart shadow. In view of the clinical symptoms including persistent high fever, skin rash, and edema of the feet and hands in addition to lab results: high inflammatory markers, leukopenia, thrombocytopenia, high cardiac enzymes, disturbed coagulation, high D-dimer, fibrinogen, and disturbed liver function with hypoalbuminemia, all findings fulfill the definition of MIS-C (Table 1).

On day 2 of admission, she had poor perfusion, cold extremities, capillary refill $4 \mathrm{~s}$, and was hypotensive. Her electrolyte showed hyponatremia, hypokalemia, metabolic acidosis, and high lactic acid, with normal urea and creatinine. Bolus $0.9 \%$ saline was given and started on adrenalin (inotropes) intravenous infusion. She was having high-grade fever and was shivering, lethargic, drowsy, pale, and irritable. The skin rash extended to the upper chest wall, neck, and lower face with puffiness of the face, mild pitting edema of the lower limbs, and abdominal distention. Ultrasound abdomen revealed pleural effusion and ascites. SARS-CoV-2 antibody IgG came positive.

The MIS-C diagnosis was made, and she was started on pulse methylprednisolone regimen at a dose of $30 \mathrm{mg} / \mathrm{kg}$ IV infusion daily for 3 days and then shifted to oral therapy at a dose of $2 \mathrm{mg} /$ $\mathrm{kg}$ and followed by gradual tapering of the dose over 2 weeks. Repeated investigations were conducted: FBC showed bicytopenia, leucopenia mainly lymphopenia, low hemoglobin, elevated inflammatory markers, high cardiac enzymes and D-dimer, hyponatremia, hypokalemia, and low albumin. Received IV albumin infusion, IV fluid, and electrolyte correction were adjusted accordingly.

She was continued on inotrope infusion support and started on aspirin $3 \mathrm{mg} / \mathrm{kg}$ daily; IV vitamin $\mathrm{K}$ for prolonged PT and esomeprazole were added. For low hemoglobin, packed red blood cell transfusion was given. She had mild desaturation below $92 \%$ and required $2-\mathrm{L}$ oxygen $/ \mathrm{min}$.

On day 3, the interleukin-6 (IL-6) level came very high 1,826 (normal $<7$ ); she was started on anti-IL-6, tocilizumab in a dose $(12 \mathrm{mg} / \mathrm{kg}$ diluted in $50 \mathrm{~mL} 0.9 \%$ saline) intravenous infusion over $1 \mathrm{~h}$. The repeated investigations showed elevated cardiac enzymes, D-dimer, lymphopenia, thrombocytopenia, low albumin, and high inflammatory markers (Table 2). Repeated ECHO reported mild to moderate mitral regurgitation, no pericardial effusion, normal coronary arteries, and EF 60. She was started on captopril. She received another dose of IV albumin infusion, blood pressure maintained above 50 centile, and inotropes dose was reduced gradually and continued on other supportive measures.

The next day, she was alert, less irritable, talking to her mother, and tolerated oral feed. The edema gradually improved, and the skin rash faded. She was maintaining oxygen saturation at room air, and the temperature episodes became more spaced and low 
Table 1. The initial investigations result

\begin{tabular}{|c|c|c|}
\hline Investigation & Reference range & Patient result \\
\hline \multicolumn{3}{|l|}{ Blood gasses } \\
\hline $\mathrm{pH}$ & $7.35-7.45$ & 7.378 \\
\hline $\mathrm{HCO}_{3}, \mathrm{mmol} / \mathrm{L}$ & $21-28$ & 18.4 \\
\hline $\mathrm{PCO}_{2}, \mathrm{~mm} \mathrm{Hg}$ & $35-45$ & 32.0 \\
\hline $\mathrm{PO}_{2}, \mathrm{~mm} \mathrm{Hg}$ & $83-108$ & $\mathrm{PO}_{2} 36.4$ \\
\hline \multicolumn{3}{|l|}{ FBC } \\
\hline Total WBC, $\times 10^{3} / \mu \mathrm{L}$ & $5.0-15.0$ & 3.6 \\
\hline Absolute neutrophil, $\times 10^{3} / \mu \mathrm{L}$ & $1.5-8.0$ & 3.3 \\
\hline Absolute lymphocyte, $\times 10^{3} / \mu \mathrm{L}$ & $6.0-9.0$ & 0.2 \\
\hline RBC & $4.00-5.20 \times 10^{6} / \mu \mathrm{L}$ & $4.43 \times 10^{3} / \mu \mathrm{L}$ \\
\hline $\mathrm{MCV}, \mathrm{fL}$ & $72.0-84.0$ & 68.8 \\
\hline Hemoglobin, g/dL & $11.1-14.1$ & 10.0 \\
\hline Platelets, $\times 10^{3} / \mu \mathrm{L}$ & $200-490$ & 190 \\
\hline Reticulocyte count, \% & $0.5-2.5$ & 1.68 \\
\hline \multicolumn{3}{|l|}{ Coagulation profile } \\
\hline $\mathrm{PT}, \mathrm{s}$ & $12.1-14.5$ & 16.1 \\
\hline APTT, s & $33.6-43.8$ & 34.2 \\
\hline INR & $0.92-1.14$ & 1.32 \\
\hline D-Dimer & $<0.5 \mu \mathrm{g} / \mathrm{mL}$ FEU & $5.34 \mu \mathrm{g} / \mathrm{mL}$ \\
\hline Fibrinogen, mg/dL & $162-401$ & 498 \\
\hline \multicolumn{3}{|l|}{ Inflammatory markers } \\
\hline Procalcitonin, ng/mL & $<0.05$ & 25.65 \\
\hline $\mathrm{CRP}, \mathrm{mg} / \mathrm{L}$ & $<5.0$ & 159.4 \\
\hline $\mathrm{ESR}, \mathrm{mm} / 1 \mathrm{~h}$ & $0-20$ & 45 \\
\hline Ferritin, ng/mL & $4.01-405$ & 288 \\
\hline $\mathrm{LDH}, \mathrm{U} / \mathrm{L}$ & $145-370$ & 260 \\
\hline Triglyceride, mg/dL & $44-197$ & $44-197$ \\
\hline Random glucose, mg/dL & $60-100$ & 137 \\
\hline Creatinine, $\mathrm{mg} / \mathrm{dL}$ & $0.3-0.9$ & $<0.2$ \\
\hline Urea, mg/dL & $12-40$ & 13 \\
\hline Serum $\mathrm{Na}+, \mathrm{mmol} / \mathrm{L}$ & $131-145$ & 126 \\
\hline Serum K+, $\mathrm{mmol} / \mathrm{L}$ & $3.2-5.4$ & 3.8 \\
\hline Serum $\mathrm{Cl}-, \mathrm{mmol} / \mathrm{L}$ & $96-111$ & 97 \\
\hline Bicarbonate, $\mathrm{mmol} / \mathrm{L}$ & $20-28$ & 16.2 \\
\hline Lactic acid, mmol/L & $0.5-1.6$ & 2.8 \\
\hline \multicolumn{3}{|l|}{ Liver function test } \\
\hline Total bilirubin, $\mathrm{mg} / \mathrm{dL}$ & $0-1.0$ & 0.3 \\
\hline Total protein, $\mathrm{g} / \mathrm{dL}$ & $6.0-8.0$ & 5.8 \\
\hline Albumin, g/dL & $3.8-5.4$ & 3.1 \\
\hline $\mathrm{ALT}, \mathrm{U} / \mathrm{L}$ & $0-33$ & 76 \\
\hline AST, U/L & $0-48$ & 45 \\
\hline GGT, U/L & $<19$ & 16 \\
\hline Alkaline phosphatase, $\mathrm{U} / \mathrm{L}$ & $<281$ & 152 \\
\hline \multicolumn{3}{|l|}{ Cardiac enzymes } \\
\hline Troponin T, ng/L & $<14$ & 3 \\
\hline NT-proBNP, pg/mL & $<125$ & 768 \\
\hline $\mathrm{CK}, \mathrm{U} / \mathrm{L}$ & $0-228$ & 26 \\
\hline CMV antibodies & IgG positive, IgM negative & \\
\hline EBV antibodies & IgG positive, IgM negative & \\
\hline Parvovirus B19 antibodies & IgG positive, IgM negative & \\
\hline Coxsackie virus antibody & IgG positive, IgM negative & \\
\hline Blood culture, urine culture, stool culture & All negative & \\
\hline Blood group & A negative & \\
\hline
\end{tabular}

FBC, full blood count; WBC, white blood cell; RBC, red blood cell; MCV, mean corpuscular volume; PT, prothrombin time; APTT, activated partial thromboplastin time; INR, international normalized ratio; CRP, C-reactive protein; ESR, erythrocyte sedimentation rate; $\mathrm{LDH}$, lactate dehydrogenase; ALT, alanine transaminase; AST, aspartate transaminase; GGT, gamma-glutamyl transferase; CK, creatine kinase; CMV, cytomegalo virus; EBV, Epstein-Barr virus. 
Table 2. Summary of investigation outcome

\begin{tabular}{|c|c|c|c|c|c|c|c|c|}
\hline FBC & On admission & Day 1 & Day 2 & Day 3 & Day 4 & Day 7 & Day 10 & Follow-up day 21 \\
\hline WBC & 3.6 & 2.7 & 16.6 & 13.1 & 22.1 & 13.0 & & \\
\hline $\mathrm{HB}$ & 10.0 & 8.1 & 11.1 & 10.2 & 10.7 & 12.6 & & \\
\hline Platelets & 196,000 & 156,000 & 201,000 & 133,000 & 143,000 & 230,000 & & \\
\hline Neutrophil absolute & 3.3 & 2.2 & 13.8 & 11.0 & 19.1 & 4.4 & & \\
\hline Lymphocyte absolute & 0.2 & 0.3 & 0.5 & 1.9 & 2.4 & 7.7 & & \\
\hline CRP & 159.4 & 321.8 & 196.1 & 70.6 & 26.5 & & & \\
\hline PCT & 25.65 & 104.96 & 79.03 & 37.64 & 2.38 & & & \\
\hline ESR & 45 & & & & 12 & & & \\
\hline \multicolumn{9}{|l|}{ Liver function test } \\
\hline Bilirubin, total & 0.3 & 0.2 & 0.3 & 0.3 & 0.3 & 0.2 & & \\
\hline SGPT (ALT) & 76 & 96 & 79 & 53 & 44 & 35 & & \\
\hline Total protein & 5.8 & 5.4 & 6.0 & 5.4 & 5.5 & 6.0 & & \\
\hline Albumin & 3.1 & 1.8 & 2.2 & 2.4 & 2.7 & 3.0 & & \\
\hline \multicolumn{9}{|l|}{ Cardiac enzymes } \\
\hline Troponin & 3 & & 55 & 31 & 16 & 29 & 10 & \\
\hline NT-proBNP & 768 & & 13,839 & 13,743 & 10,727 & 1,348 & 421 & 29.4 \\
\hline \multirow[t]{2}{*}{ D-Dimer } & 21 September 2020 & 23 September 2020 & 24 September 2020 & 25 September 2020 & 27 September 2020 & 28 September 2020 & 30 September 2020 & 15 October 2020 \\
\hline & 5.34 & 6.13 & 6.18 & 6.22 & 7.58 & 8.67 & 3.15 & 0.31 \\
\hline IL-6 & 1,826 & & & 85.10 & & & 11.90 & 8.25 \\
\hline
\end{tabular}

WBC, white blood cell; CRP, C-reactive protein; ESR, erythrocyte sedimentation rate; ALT, alanine transaminase.

grade. She could stand bearing her weight with support. The Neurology team evaluated her; there was no focal neurological deficit. All cultures were negative, and hence antibiotics were discontinued. Repeated investigations were improved except for D-dimer. The child was shifted out of the PICU.

Over the next few days, she was doing well on supportive measures, oral aspirin, captopril, oral methylprednisolone tapering dose, and vitamin D supplement. She stayed afebrile, and the oral intake gradually improved (she was on high protein and calorie diet as per clinical nutrition). Gradually, she started to walk with support and then by her own. Her speech was normal.

On the day of discharge (day 10 of admission), all the laboratory investigations were back to normal. It was noted that D-dimer was increasing until day 10 of admission. Echocardiogram was repeated and showed mild mitral regurgitation, mild tricuspid regurgitation, PFO, EF 66\%, and good, improved cardiac function, and she was continued on captopril and aspirin, She was discharged home with follow-up after 2 weeks for clinical re-evaluation and repeated IL- 6 and NT-proBNP.

Two weeks after discharge, she was doing well, no complaint, active, and walking; she was on aspirin, captopril, and vitamin D supplement. The repeated laboratory results (D-dimer, IL-6, and NT-proBNP) markedly improved. Repeated echo after 6 weeks reported to be normal.

\section{Discussion}

Since the evolution of COVID-19 pandemic, children infected with SARS-CoV-2 had mild symptoms compared to adults. In May 2020, the picture changed where children with COVID-19 showed signs of a severe and lethal form of the disease. This form mimics Kawasaki disease or toxic shock syndrome. This acute extreme form was addressed by the Royal College of Pediatrics and Child Health (RCPCH) as a pediatric multisystem inflammatory syndrome temporally associated with SARSCoV-2 (PIMS-TS) [5]. Moreover, the CDC and WHO labeled this form as MIS-C [6, 7]. Herein, we are reporting a case, 35-month-old female previously healthy, who had the symptoms and signs as well as the investigations fulfilling the diagnostic criteria of MIS-C as per the CDC.

Since mid-May 2020, CDC has been following reports of MIS-C, uncommon but robust condition associated with COVID-19. MIS-C is a recent syndrome, and many queries remain: why some children develop it after a COVID-19 illness or contact with someone with COVID-19 [8]. On April 24, 2020, the UK National Health Service announced a pediatric inflammatory multisystem disorder alert, and emergency MIS-C pathophysiology is still uncertain; potential mechanisms include the identification of self-antigens by antibodies or $\mathrm{T}$ cells resulting in autoantibodies, antibody, or T-cell recognition of viral antigens expressed on infected cells resulting in inflammation-activating immune complex formation, and the sequence of viral super antigens activating host immune cells $[9,10]$.

A systemic review, done on 39 studies, depicted clinical outcomes of MIS-C, where 469 (71\%) children diagnosed with MIS-C were reported as admitted to the ICU and only 11 deaths (1.7\%). Mechanical ventilation was 
required in $22.2 \%$ and extracorporeal membrane oxygenation in $4.4 \%$ of the patients. AKI occurred in $16.3 \%$ of the children [9].

MIS-C associated with coronavirus disease 2019 was defined in the CDC Health Advisory (COVID-19) as follows: (a) a patient aged $<21$ years presenting with fever ( $>38.0^{\circ} \mathrm{C}$ for $\geq 24 \mathrm{~h}$ or report of fever lasting $\geq 24 \mathrm{~h}$ ); (b) laboratory evidence of inflammation (elevated inflammatory markers which include one or more of the following: an elevated C-reactive protein, erythrocyte sedimentation rate, fibrinogen, procalcitonin, D-dimer, ferritin, and lactic acid); (c) evidence of severe illness requiring hospitalization, with multisystem $(>2)$ involvement (cardiac, renal, hematologic, respiratory, gastrointestinal, skin, or neurological); (d) no other possible diagnoses; and (e) positive for current or recent SARS-CoV-2 infection by PCR, serology, or antigen test or contact with a suspected or confirmed COVID-19 case within the 4-6 weeks prior to the onset of symptoms $[3,8]$.

While the Royal College of Pediatrics and Child Health RCPCH definition of pediatrics multisystem inflammatory syndrome associated with COVID-19 (PIMS-TSN) reported that the temporal association with COVID-19 does not require proof of infection or exposure to meet the case definition like the CDC and WHO criteria $[9,10]$. Children diagnosed with MIS-C had commonly cardiac involvement $[11,12]$. Our patient had mitral regurgitation, EF 65\%, and fortunately her coronary arteries were normal. However, the child progressed to hypotensive shock that required inotropes, captopril, and aspirin. SARSCoV-2 antibody IgG reported positive. She gradually improved over the next few days; ECHO follow-up before discharge showed mild mitral regurgitation, mild tricuspid regurgitation, $\mathrm{PFO}, \mathrm{EF} 66 \%$, and good, improved cardiac function. She was continued on captopril and aspirin. Two weeks after discharge, her ECHO was back to normal.

\section{Conclusion}

In this study, we are reporting a case fulfilling the criteria of MIS-C. We urge clinicians to raise their index of suspicion for cases who present with fever and elevated inflammatory markers as they are prone to have rapid progress to shock. Early diagnosis and intervention is crucial for patient survival.

\section{Statement of Ethics}

Written informed consent was obtained from the patient's parent for publishing of this case report and any accompanying images.

\section{Conflict of Interest Statement}

No conflicts of interest.

\section{Funding Sources}

No funding sources were applicable to this work.

\section{Author Contributions}

M.H. edited the manuscript. B.Y. wrote the manuscript. M.S. edited the manuscript and is the corresponding author.

\section{Data Availability Statement}

All data generated or analyzed during this study are included in this article. Further enquiries can be directed to the corresponding author.

\section{References}

1 WHO Coronavirus Disease (COVID-19) dashboard data. [last updated 2021 Mar 28]. Available from: https://covid19.who.int/. Accessed 2021 Apr 18.

2 The Supreme Council for National Security National Emergency Crisis and Disasters, Management Authority. UAE coronavirus (COVID 19) update. Available from: https:// covid19.ncema.gov.ae/en. Accessed 2021 Apr 18.

3 CDC Center for Disease Control and Prevention. Information for healthcare providers about multisystem inflammatory syndrome in children (MIS-C) partner updates. Available from: https://www.cdc.gov/mis-c/hcp/.

4 Pawar SM. Multi system inflammatory syndrome in children and adolescents temporally related to COVID-19. GFNPSS-Int J Multidiscip Res. 2020;1(3):97-102.

5 Royal College of Paediatrics and Child Health. Guidance: paediatric multisystem inflammatory syndrome temporally associated with COVID-19. 2020. Available from: www. rcpch.ac.uk/resources/guidance-paediatricmultisystem-inflammatory-syndrome-temporally-associated-covid-19.
6 Centers for Disease Control and Prevention (CDC). Multisystem inflammatory syndrome in children (MIS-C) associated with coronavirus disease 2019 (COVID-19). 2020. Available from: https://emergency.cdc.gov/ han/2020/han00432.asp.

7 World Health Organization. Multisystem inflammatory syndrome in children and adolescents with COVID-19. [published 2020 May 15]. Available from: www.who.int/publications-detail/multisystem-inflammatory-syndrome-in-children-and-adolescents-withcovid-19. 
8 CDC Center for Disease Control and Prevention. Reported by Jurisdiction MC. Health department-reported cases of multisystem inflammatory syndrome in children (MIS-C) in the United States. [last updated 2020 Sep 17]. Available from: https://www.cdc.gov/mis-c/ cases $/$ ? deliveryName =USCDC_2067 DM37553?ftag=MSF0951a18.
9 Ahmed M, Advani S, Moreira A, Zoretic S, Martinez J, Chorath K, et al. Multisystem inflammatory syndrome in children: A systematic review. EClinicalMedicine. 2020 Sep 1;26: 100527.

10 Jiang L, Tang K, Levin M, Irfan O, Morris SK, Wilson K, et al. COVID-19 and multisystem inflammatory syndrome in children and adolescents. Lancet Infect Dis. 2020 Nov;20(11): e276-88.

11 Belhadjer Z, Meot M, Bajolle F, Khraiche D, Legendre A, Abakka S, et al. Acute heart failure in multisystem inflammatory syndrome in children (MIS-C) in the context of global SARS-CoV-2 pandemic. Circulation. 2020; 142(5):429-36.
12 Vari D, Miller JM, Rellosa N, Srivastava S, Frizzola M, Thacker D. Severe cardiac dysfunction in a patient with multisystem inflammatory syndrome in children associated with COVID-19: retrospective diagnosis of a puzzling presentation. A case report. Prog Pediatr Cardiol. 2020 Sep 1;58:101270. 